João Vicente, Lieutenant-Colonel, Security and Defense Research Center, Joint Command and Staff College, Portugal, Scheduled to defend his PhD dissertation in New University of Lisbon.

\title{
THE AMERICAN WAY OF REMOTE AIR WARFARE
}

\begin{abstract}
This analysis will assess the effects of the American way of Remote Air Warfare on the decision to wage war and the factors affecting the tactical conduct of war. This will be accomplished by determining how the Remote Air Warfare operational template influences the decision making process at the strategic level, by analyzing the political willingness to wage war, and at the tactical level, by assessing how the distance from the battlefield impacts warfighter's proneness to use lethal force.

This operational template translates the double moral implications of the increasing distance and removal of human risk from the duel. On the other hand, exposes a political maneuver's expansion of freedom, increasing the propensity to wage war and changing the relationship between state and society.

The research was guided by an inductive methodology of prospective nature, which analyses the past to inform present decisions, aiding to formulate future strategic actions. Thus, performing a critical analysis of the ideas underlying the employment of airpower, within an operational template of Remote Air Warfare, will facilitate the development of a comprehensive knowledge about its effects and a more effective adaptation to future war.
\end{abstract}

\section{Keywords}

Remote Air Warfare, Airpower, Unmanned Aircraft Systems, Targeted Killings, War.

\section{Introduction}

There are numerous problems which affect international relations. We are confronted daily with unsolvable phenomena such as climate change, migration, globalization or systemic financial crisis, which seem to centralize the attention of scholars of Social Sciences. However, the conduct of war and its results deserve the same kind of analytical rigor, not only because war affects politics and society, but because the effects of victory and defeat are disproportionate (Biddle, 2004:207). 
Within the scope of this article we have adopted the perspective of international relations concerned with the political, economic and social relations between different actors in the international system, with particular emphasis in the states. Furthermore, we consider this concept in its narrow sense as the relations in which states try to defend their interests. From the various dimensions of the concept, we choose to focus our analysis in the relationship which expresses the ultimate consequences for international security: war. Considering that within the context of international relations information is an important source of power, it is easily foreseen the impact of a persistent surveillance capability in preventing and combating security threats.

In less than a decade, the number of military Unmanned Aircraft Systems (UAS) has increased from a few dozens to thousands of systems employed by all branches of the armed forces, and even civilian organizations. The global spread of UAS is revealed today by the employment of American drones in combat, simultaneously and discreetly, in several theaters, expressing the emergent tendency for a risk free, unilateral war, aseptic for the offensive, lethal to the enemy, and with reduced collateral damage. This is the promise and the reality of Remote Air Warfare where the new interface of war is a high definition image on a computer screen, somewhere in an air conditioned bunker, thousands of miles away from the impact of the bomb.

The analysis of evolving patterns of warfare gives military and civilian leaders the understanding about how future adversaries may think and act, allowing for effective strategic planning. Thus, performing a critical analysis of the ideas underlying the employment of UAS, within an operational template of Remote Air Warfare, will facilitate the development of a comprehensive knowledge about their effects and a more effective adaptation to future war. In this sense, many of the current and future innovations in the Remote Air Warfare arena demonstrate the potential to radically alter the processes of war - when and why is fought, how is fought and by whom is fought.

In order to achieve our objective, this analysis will assess the effects of the American way of Remote Air Warfare on the decision to wage war and the factors affecting the tactical conduct of war. This will be accomplished by determining how the Remote Air Warfare operational template influences the decision making process at the strategic level, by analyzing the political willingness to wage war, and at the tactical level, by assessing how the distance from the battlefield impacts warfighter's proneness to use lethal force. Therefore, it will unveil effects at the 
operational level, with impact on the conduct of war; genetic effects reflected in the change of airpower characteristics and capabilities, and political and social effects which impact the decision making process about the use of force. The analysis exposes the coming era of "drone diplomacy" in which Remote Air Warfare may be the preferred political operational template, promising to offer a solution for limited use of force against individuals and less developed societies.

When equating the research methodologies in international relations we are faced with an array of comprehensive processes and tools that can be applied individually or combined in the form of a scientific method of knowledge production. Unlike Exact Sciences in which it only satisfies a quantitative solution to a problem, the issues of human interaction and in particular its most lethal behavior - war - often only allow the assessment of trends, in order to qualitatively extrapolate their future impact.

Aware of this methodological diversity, we chose a pragmatic perspective which examines problems in international relations as a tool to support policy making and decision. This perspective acts as a prospective instrument which analyses the past to inform present decisions, aiding to formulate future strategic actions. Hence, this research was guided by an inductive methodology of prospective nature. This is done through the collection of relevant facts about the particular object of study followed by a systematic observation and analysis. This will allow the employment of a systemic approach which in addition to considering the nature of interactions also exposes its effects. The sources used in the research include official reports, media figures and statements, as well as academic articles and books.

\section{Conceptual framework: War and Airpower}

There is more to war than warfare. Clausewitz's view of war as a political act expresses the commitment of a westphalian system where respect for absolute sovereignty, diplomacy and legitimacy of international treaties were cornerstones (Keegan, 1994:5). In this record, Clausewitz (1989:75) assures us that war is an act of force to compel the enemy to agree with our will. This instrumental perspective of war, as the political expression of the use of force, enhances the attractiveness of using force as a rational decision to coerce the opponent to do something that he wouldn't naturally do.

Within this construct, war is usually characterized by a substantial number of casualties, and high intensity fighting. Therefore, war can be defined in terms of violence, and its most dominant consequence, the loss of human life. So, the 
prospect of war as a clash of wills, involving an act of force over time to compel or coerce an adversary to do our will, expresses the key component of violence. As a political rational act it must be submitted to certain rules in order to be legitimized as a human activity.

Clausewitz's convictions (Ibidem:75;149) on the fact that war is a bloodshed physical confrontation between two opponents makes it unlike any other form of conflict or competition. War is a form of hostile conflict, with high human costs, politically and publicly scrutinable in Western democratic societies. The assumption of physical risk, ultimately risking life itself, inherent in the military profession, distinguishes war from other human activities.

In this sense, war is the most extreme, more intense, comprehensive and sustained form of combat between two parties, usually states. Thus, war is seen as an organized activity, subject to rules and rituals, where violence is employed by collective social organizations in a focused way (Vasquez, 1993:24-25).

War as an act of violence between two belligerent transcends the methods or techniques of force application (warfare). Clausewitz's trinitarian nature of war exposes its constants: passion (emotion, enmity and hatred) affected to the population, the risk (uncertainty, luck, danger and effort) associated with the military, and the political reason of who establishes the goals and leads the conduct of war. This triangle of passion, risk and reason expresses the unchanging nature of war. Hence, as long as this equation includes such factors like violence, the strategic calculus of the military commander, and the political instrument dominated by reason, we will witness the continuation of the historical trend.

Fog and friction, as fundamental and immutable attributes of war, distort the perception and execution of military operations (Clausewitz, 1989:77-83). Ignorance and uncertainty about the opponent, the environment, or its own forces, resulting from excess or lack of information, incorrect assumptions, or unexpected adversary actions, express the characteristic fog of battle. Friction differentiates "war on paper" from reality, expressing factors which influence the implementation of the plan, such as topography, weather, fear or confusion. These attributes transform combat in a complex and chaotic activity, where a myriad of small details can have a direct impact on the success of operations. In combat, human error, motivated by fear, anger, stress, disorientation or incompetence, can crumble the most elaborate plans. Technology, in particular the networking of sensors, decision makers and effectors can contribute to reduce, but not eliminate, these uncertainties and complexities. 
This comes in line with Clausewitz's (Ibidem:593) reminder about the importance of context by stating that every age has its own form of warfare, its own limiting conditions, and preconceptions. Within this framework, airpower has emerged in the American way of war as a preferred political instrument to wage wars.

In order to understand the impact of those changes we need to consider airpower under an operational template with strategic relevance, and always keeping in mind the contextual lenses of each era. An operational template includes technology, people and theory. The interaction between these components helps solving a specific strategic problem. Thus, using the scientific approach and the technologies of the Industrial Age as contextual lenses, the strategic bombing operational template became both the solution to the strategic challenges posed by World War I as well as the only justification for the independence of the Air Force.

World War I revealed the increased lethality of war, mainly due to the technological advances of the Industrial Revolution, coupled with the lack of new ideas on how to reduce their power. Accordingly, after the disappointment about the massacre of World War I, the prevailing thought was to prevent further occurrences of such tragedy. Thus, several attempts were made to defend a new operational template using a new technology - the airplane. During the interwar period, Billy Mitchell, in his crusade to promote airpower, launched the international discussion, in line with other thinkers like Giulio Douhet or Hugh Trenchard, that aviation could provide the ability to "jump over the enemy" and directly attack his will to resist, by achieving the vital centers of the opponent, paralyzing them, and making it impossible for the population to continue waging war or live in peace (Hurley, 1975:111). So, the concept of strategic bombing was thought to be the decisive method to impose the will, and the bomber its instrument.

The idea behind the thoughts of theorists was that the strategic nature of airpower and its offensive nature required institutional independence. However, this fixation led to an exaggeration of capabilities and assumptions. This cognitive dissonance dismissed contradictory information that could harm the efforts of independence, promoting thinking which would not to disturb the validity of strategic bombing (Biddle, 2002:5).

The American approach to strategic bombing was built on the promise of precision, coupled with the desire to avoid civilian casualties. However, the "fog and friction" of war revealed the vulnerability of bombers to enemy air defenses, and its vagueness to attack targets deep in the heart of the enemy. Furthermore, the desired 
effect on opposing society did not occur as planned (Ibidem:291). Therefore, adjustments had to be made to the operating template, changing the emphasis from destruction of key infrastructures to bombing cities. This change in tactics was the recognition of the limits of technology and also the failure of the doctrine of strategic bombardment.

The reality of World War II was that the plane could not give a decisive victory. Nonetheless, historical record shows that the theory of airpower precedes technology. For example, the doctrine of strategic bombardment was conceived long before the development of the bombers. Furthermore, the precision bombing and strategic paralysis concepts, related to the destruction of industrial targets, only became effective with the advent of guided munitions. Although the strategic bombing operational template was not decisive, the use of nuclear bombs unleashed the technological potential of airpower as a decisive instrument of war, realizing all the promises of earlier theorists.

The Cold War period was sustained by constant advances in technology. However, the United States Air Force (USAF) participation in limited wars, as in Korea or Vietnam, did not show the expected decisive results. Some supporters rushed to explain that these wars were abnormalities, on which there were numerous political interferences and constraints (Ibidem:296-299).

Again, the central theme of strategic bombing was renovated during the 1990s, when the experiences of Desert Storm, Bosnia and Kosovo, announced a new revolution in military affairs. Under the contextual lenses of defense transformation, information technology, and in particular precision bombing, finally fulfilled the promises of strategic bombing, showing the determination of airpower and giving the false impression that, by itself, could win a war.

In this long record of technological charm, UAS appear as a natural evolution for a new air warfare operational template, waged at increasing distances, with less risk to crews and reduced collateral damage.

With this conceptual framework in mind, we have set the necessary analytical background upon which we can discuss the essence and implications of the American Remote Air Warfare's operational template. 


\section{The quest for Remote Air Warfare}

In the twentieth century there were several attempts to develop and deploy UAS, but this path was marked by inconsistency, where short periods of major investments in the development and limited operational employment contrasted with long periods of forgetfulness. In 1970, a USAF study predicted that in the following 15 years the UAS would complement, and in some cases, supplant the traditional missions of the Air Force (Ehrhard, 2010:43). Long before that, in 1956, another study forecasted that future combat aircraft would become technologically obsolete (Ibidem:4). However, these views are not yet confirmed, forcing to question the reasons for such failures.

Clark (2000) highlights factors such as technological deficiencies, management impediments, political reluctance, lack of cooperation between the military branches, pilot's skepticism, competition among weapons systems, costeffectiveness, and lack of operational need, as being responsible for the episodic nature of UAS in the twentieth century. Also Cohen (2007:143), when investigating the reasons that dragged on for more than three decades the process of introducing this capability in the structure of the military, finds a spectrum of varied explanations. Whether by technological immaturity, which has diminished the relevance and reliability of these operating systems, or the lack of an obvious operational need for its employment, or even cultural opposition by pilots averse to the introduction of unmanned technologies, the truth is that none of these reasons, by itself, is fully satisfactory.

In fact, the development of military technology is subordinate to the way of war of a particular culture, as well as to the strategic environment in which it forecasts the use of force. In this sense, a confluence of political, economic and technological factors gave a decisive impetus to overcome the historical inertia of UAS development. Consequently, the contemporary prominence of UAS may be attributed to an ignition moment and several detonator events.

The American appetite for technological solutions of war constitutes the ignition moment of another military revolution, not in the sense of the rapidity in which the change occurs, but due to the magnitude of its effects. The first detonator event, and perhaps the most profound, occurred on September 11, 2001 when the US initiated the Global War On Terrorism, establishing the military instrument as the primary response method. However, the military apparatus, hitherto designed to destroy any opposing army, was not entirely appropriate to wage limited irregular 
wars. Sustained by exponential technological advances and wartime budgets, the UAS found a niche operation for which they were especially gifted. Thus, while September 11 catalyzed the need for UAS, the operational usefulness of these capabilities in two irregular conflicts, catapulted its value. In parallel, the overwhelming support of the political-military leadership, removed the existing historic barriers against the development of a Remote Air Warfare operational template.

In this regard, the last decade exposed the basic ingredients for a revolution: the operational need, adequate financing, and the adaptation in the introduction of new capabilities in combat. In addition, the new US strategy provides the necessary support for the accelerated development of new capabilities and innovative forms of employment, confirming the crossing of a point of no return.

As a result of increasingly urgent operational demands, from 2006 to 2010 the US defense budget tripled, and so did the number of hours flown in theaters. Likewise, the budget of the Department of Defense (DoD) for the development and acquisition of UAS increased from $\$ 667$ million dollars in the fiscal year 2001 to $\$ 3.9$ billion dollars in the 2012 budget, while the inventory of 167 systems in 2002 exploded to 7,500 in 2010 (Gertler, 2012:2).

The escalating operational use of UAS in several theaters is revealed by the number of hours flown by systems such as the Predator, Reaper and Global Hawk operated by the USAF. It took 12 years (1995-2007) to achieve the first 250,000 hours of flight. In the following two years another 250,000 hours were flown. In 2010 alone, over 250,000 hours were completed. The current status of UAS, as weapon systems of choice, is evidenced by the accomplishment of more than one million hours in combat by March 2011. While it took 14 years to overcome this hurdle, it is expected that this number will double in just two and a half years (Schanz, 2011:36).

However, we cannot overlook the fact that operational utility has associated costs. When speaking of UAS we have to consider something more than a simple platform. That is, to compare the cost of a manned aircraft with a drone is misleading, since the latter is only able to perform its function when operating as part of a comprehensive system, including the human element, the control station, as well as the communications and command and control links. Unlike manned aircraft, these system elements are an essential prerequisite for the operation of UAS. 
Thus, the notion that UAS operations saves resources must be put into perspective, since savings depend on the type of system, the mission in which is employed, configuration and type of desired effects. Portable systems, organic to ground forces, have acquisition and operating costs well below manned aircraft. As we rise through the capabilities offered, sensor types, weapons and remote split operation over several geographical locations, so does, exponentially, the cost. The same rule applies to the human resources involved in the operation and exploitation of the operational product provided by the UAS. For example, maintaining a 24 hours long Reaper orbit (combat air patrol) may require up to 192 people, divided in launch and recover, control, processing, exploiting, and dissemination activities (Gear, 2011).

Hence, the seductive vision of a disposable platform seems not to reflect the current situation and future prospects, at least when concerning operational and strategic level UAS. The use of platforms whose destruction is tolerable in terms of financial costs, and above all, in terms of human resources, quickly transformed UAS as high demand/low density (availability) assets, forcing to prioritize its operational allocation and employment. Along with the added operational value, as the result of a broader spectrum of missions, the technological value of UAS also increased to the point of risking human lives to retrieve lost platforms in enemy territory (Geete, 2009). Additionally, the recent case of a lost RQ-170 Sentinel, and its capture by Iran, adds significant challenges about the problem of technology transfer and proliferation.

From a political perspective, the incentive for UAS proliferation is enshrined in the American defense strategy documentation. Following the approach initiated with the 2006 Quadrennial Defense Review, the DoD decided to double the coverage of UAS, and so the 2010 version distinguishes these systems as one of the key capabilities to allow the US military to perform its mission, against current and potential adversaries (US DoD, 2010:18). The final boost, which confirms the irreversibility of Remote Air Warfare, occurred with the definition of the new US military strategy. The shift of the military emphasis toward the arc of Pacific forces the increase of surveillance and long-range strike capabilities in order to minimize the impact of anti-access/area denial adversary strategies. Also, the global fight against terrorism, will continue to depend on the capabilities offered by UAS, since the US assumes the need to monitor the activities of non-state global threats, in order to control, and if necessary, attack dangerous individuals (US DoD, 2012a:1). 
Judging by the investments made and planned by $\mathrm{DoD}$, it is possible to confirm this point of no return. The plan to acquire, by 2020, 730 new medium/large UAS, while pending modernization of existing systems, requires an investment of $\$ 36.9$ billion dollars (CBO Study, 2011:vii). For example, considering only three essential systems, in 2012 the USAF had 23 Global Hawk, 163 Predator and 70 Reaper in its inventory (US DoD, 2012b:2), which is expected to reach the total of 650 systems in 2021 (Gertler, 2012:4). Furthermore, we should not forget that a similar progression occurs in other DoD services, as new systems are developed and introduced in operations.

The USAF strategic vision (USAF Flight Plan, 2009) makes us believe that we are about to cross the fine line between innovation and revolution. However, the mere increase in the number of platforms does not reflect the magnitude of this moment. Future systems, already under development, are not mere adaptations of current UAS, but the reflection of three essential attributes of modularity, new operational functions, and autonomy, allowing for the most suitable combination, in an aerial platform, of weapons and sensors that enhance mission effectiveness.

\section{US political seduction for Remote Air Warfare}

The military instrument exists to impose the will of a regime over another, in order to coerce the opponent to change his opinion, through a spectrum of options that extends from humanitarian support to the use of offensive lethal force. The ability of the military to find and destroy things at a distance never stopped amazing American politicians (Zenko, 2010). The American political tendency to resort to limited military contingents, when confronted with challenges that threaten national interests, is being taken to the limits with the increasing use of Remote Air Warfare. This is not disparate with the fact that these systems are a relatively lowcost option, always available, and with high operational effectiveness.

In this sense, Predator and Reaper drones are for the Obama administration a technological evolution of what cruise missiles represented for President Clinton in the 90s of the last century: a form of prosecuting a muscular foreign policy, but without the high costs associated with the employment of ground forces. This political ambition is one of the catalysts for the future preeminence of UAS and above all to boost the development of more capable systems, particularly in terms of reach, persistence and autonomy.

The current political preference for Remote Air Warfare can be verified in practice, noting that in late 2011 the US employed armed drones, simultaneously and 
continuously in six different theaters ${ }^{1}$, in addition to conducting surveillance missions in several countries, including domestically. In this context, the operation in air permissive environments, where the threat to the drone is minimal, with tacit or explicit support of local governments, maximizes the ability of persistence in gathering intelligence and eventual attack of emerging targets.

In the preceding moments of the political decision to wage war, we are faced with two essential demotivation factors: the interest at stake and the cost depleted, expressed in "blood and treasure". One of the limiting reasons for an aggressive military policy has to do with the risk to its own forces. The emphasis of Western populations and politicians to find relatively safe ways to use lethal force, such as artillery and aerial bombardment, suggests that they value more friendly military casualties than adversary civilian victims (Olsthoorn; Royakkers, 2011).

As instruments of coercive diplomacy, that is, within the realm of deterrence and compulsion, the employment of armed UAS, by reducing the potential costs of the threat and use of force, may have substantial implications (Nolin, 2012:13). Particularly in situations of greater asymmetry between the actors in dispute, and considering that there are practically no human costs for the attacker, the credibility of such threats will be strengthened, since the use of force occurs more easily and without the time-consuming political and public scrutiny associated with the employment of traditional means. Likewise, it is expected that states possessing armed UAS may become bolder and resort more frequently to employ Remote Air Warfare, as a preventive and primary instrument of conflict resolution.

Furthermore, the use of UAS translates a smaller military "footprint" which may be politically attractive. The concept of remote operation and the features associated with the UAS, which facilitate long-range attacks, allow a reduction in the number of forward bases for power projection. Without this strategic requirement, it also reduces international interference and the obligation to gather broad consensus and even coalitions to support the use of force.

The American adventure in Iraq and Afghanistan demoted the appetite for invading tribal areas in Pakistan. However, the need to replace the conventional option by a widely acceptable political solution, catapulted UAS to a level of urgent operational requirement. This has given way to a modality of "Clandestine Wars", not declared, fought outside active theaters of operations, and developed under the form of targeted killings of terrorists, carried out by drones, operated by a civilian

\footnotetext{
${ }^{1}$ Libya, Iraq, Afghanistan, Pakistan, Yemen, and Somalia.
} 
organization and Special Forces in remote areas of Pakistan, Yemen or Somalia. Since 2002 more than four hundred attacks were carried out only in those theaters, highlighting the primordial status of this tactic in the American strategy of Remote Air Warfare (New American Foundation, 2012).

The drone campaign of targeted killings began in November 2002 with an attack in Yemen. It was also in this country that occurred the first killing of an American citizen. The operational secrecy, provided by the Central Intelligence Agency's (CIA) air campaign, along with the unaccountability of actions, seem politically seductive to the Obama administration in order to spread the use of Remote Air Warfare. However, the employment of this operational template has some shortcomings.

Although Remote Air Warfare may be considered extremely precise when compared with other types of warfare or even with the historic record of aerial bombing, we must not forget that there are always instances where the "fog and friction of war" create collateral casualties. No matter how advanced the conduct of war or the innovations which are introduced into the art of war, collateral damage and fratricide will always be two inseparable constants. So, the central question must be what level of civilian casualties is acceptable. The answer is always dependent on the interests at stake, the value of the target, and the consequences of acting or not.

One of the main challenges in accounting and categorizing casualties in a distant conflict, waged in remote tribal areas, inaccessible to independent and impartial bodies, has to do with the different perspectives of the parties in conflict. While Washington declares most of the casualties as insurgents, the critics claim that the majority of the casualties are civilians. Additionally, the complexity of this process increases due to the difficulty in qualifying the status of the targets (as combatants or not), as a result, for example, of the tactics employed by insurgents by diluting themselves among the population. According to The Bureau of Investigative Journalism, between 2004 and November 2012 the reports of fatalities caused by 350 CIA drone strikes, only in Pakistan, range from 2,593 to 3,378, of which 475 to 885 were civilians. However, according to the New American Foundation, in the same period, the 337 attacks recorded caused between 1,908 and 3,225 fatal victims, $16 \%$ of which were civilians.

Regarding collateral damage, we may argue that civilian casualties are relatively low when compared with previous conflicts, and if considering alternative options for action, including the employment of ground forces. Avery Plaw (2010:11) 
makes this argument based on an analysis of the patterns of proportionality concerning drone attacks in Pakistan between 2004 and 2007 and other tactics and conflicts, pointing to a greater discrimination of non-combatants in the campaign of targeted killings. The results indicate a ratio of 17:1 in casualties among insurgents/combatants and civilians in the use of drones against ratios of 4:1 in the 2009 Pakistani offensive with special forces, 3:1 in the operations of the Pakistani Army between 2002 and 2007, 1.5:1 in the Israeli program of targeted killings from 2000 to 2009 , or 0,125:1 to all armed conflicts that occurred in 2000 .

Within this perspective, the relevance of Remote Air Warfare, or other operational template, must be determined according to their usefulness to prevent a conflict, and in the event that it occurs, at limiting civilian casualties to a minimum, which means decreasing the bloodshed in war, and ensuring and strengthening the humanitarian code of conduct. Furthermore, civilian casualties are hardly justifiable as Western societies grow accustomed and expect surgical precision, especially if the use of force is not perceived as just, or if it is employed in a conflict in which war was not declared, outside active theatre of operations, and by non-military organizations.

In the American counterterrorism campaign the goal is not to compel al-Qaeda to stop their terrorist activities, but to reduce its actual capacity to materialize such threats. In the perspective of the administration, the number of insurgents killed and psychological constraints imposed on their movements and contacts demonstrate the effectiveness of such tactic. Moreover, the successive annihilation of terrorist leaders hinders the rise of experienced elements and as such reduces the threat of large-scale terrorist actions (Brennan, 2012). In this sense, the terrorist organization is severely affected after a decade of targeted killings, the vast majority through remote aerial bombardment.

The rationale advocated by some government officials to employ lethal force in counterterrorism operations is based on the 2001 Congress authorization, which attributed to the President the power to use all necessary and appropriate force against terrorist groups, to protect the US from any imminent threat. Moreover, this legal framework only refers to those who planned, authorized, committed or aided the terrorist attacks of September 11. However, after more than ten years, there is some difficulty in confirming the relationship of the current groups associated with al-Qaeda with the events of that date. Thus, more than a decade after the 2001 Congress Act, the administration still holds the same legal framework for a conduct which allows the government to attack any target, anywhere in the world, anytime. 
These optimistic views perceive the employment of UAS as the most precise and effective use of military force against insurgents. However, the flexibility and adaptability of terrorist networks hamper the goal of disrupting the tactical level. In addition, new leaders will tend to become more radical, both in speech and in the execution of terrorist acts. Similarly, collateral damage induces an alteration of the population allegiance towards greater support for insurgents. Many question the effectiveness of such a campaign, since these groups do not have limited political objectives, and therefore, are not likely to be deterred or constrained (Nolin, 2012:13). So, until it becomes possible to tackle the ideology of al-Qaeda, as well as the state support it receives and its ability to explore ungoverned spaces, we shouldn't expect to be able to defeat this threat.

Furthermore, the danger of treating the world as a battlefield is that it encourages other countries to follow the same example. Regardless of the legal judgments that can be made about the operation of drones by the CIA, in a moral and political perspective, the US loses its legitimacy to judge similar conducts from other countries. As today we are witnessing American drones overflying Pakistan, Yemen and Somalia, it will not be unreasonable to think, in theory, that in the future other countries or organizations may do so over New York or Washington. Thus, the possibility of other states and non-state actors pursuing similar conduct against American interests compels the US to consider possible alternatives to minimize adverse effects of the proliferation of UAS. Among them stand out the establishment of standards for use, just like for the use of nuclear weapons; a policy of counter proliferation, as done in the advent of cruise missiles, or limiting its efforts to the adoption of tactical countermeasures against adversary systems.

Besides the legal analysis, which is not the aim of this article, the US loss of legitimacy implies the sacrifice of support from other states and galvanizes the terrorist cause, increasing their recruitment base. It is our understanding that in spite of the clarifications provided by the Obama administration in recent months about the decision-making process and attack protocols, the truth of the matter is that the factual evidence disseminated about those methodologies is clearly insufficient, and are not likely to be substantiated by independent sources. Thus, this American global sovereignty perspective threatens to superimpose itself over the traditional entitlement of individual state sovereignty.

The history of fighting irregular conflicts may question the minimalist approach of use of force based upon UAS, cruise missiles, Special Forces and a reduced military force on the ground. In addition, the lack of a human face in Remote Air 
Warfare prevents direct contact with the population and undermines the reconstruction efforts. Regardless of being impossible to establish a direct causeeffect, it's possible to anticipate an erosion of the American credibility in the region that gradually will expand worldwide.

Regarding the strategic utility of Remote Air Warfare in coercing states to change their behavior, we are still far from being able to accurately assess this option. As airpower in its broader application still does not guarantee success by itself, is unlikely that the single-handedly employment of Remote Air Warfare will constitute an effective alternative to the combined use of other instruments of power. However, by appraising the political and operational benefits aforementioned, it is easily understood that UAS will be an essential capability to enhance battle space situational awareness, while enabling the application of lethal force, discreetly and accurately. This ubiquity and persistence may themselves deter potential aggressors.

Given the relative infancy of UAS, for now, only the US has the capability to engage and sustain such global air campaigns. However, the global proliferation of UAS fleets will facilitate the replication of such military actions. Since 2005, the number of countries that have acquired UAS nearly doubled, totaling 76 in 2012, while over 50 countries are responsible for the development and production of more than 900 types of UAS (US GAO, 2012:9-14). The leading exporter of drone technology is Israel, having already spread advanced systems to more than a dozen countries, while assisting others in developing their own capability. Meanwhile, it is also satisfying the growing trend of leasing UAS services in operational theaters. For its part, the US exported sophisticated UAS to six countries, some of which in the most lethal version, finding in this global market an attractive source of revenue for its defense industry.

Consequently, the future looks promising indeed for nations that until now did not have enough resources to maintain a portfolio of offensive air capabilities. This will entail a change in the regional power dynamics, allowing the expansion of the capabilities of smaller, but wealthy, nations.

In trying to summarize how the nature of the political debate changes with the growing use of Remote Air Warfare, we find that the advent of UAS can facilitate the policy-making process regarding the use of force, since it offers the possibility of employing military capabilities in a conflict without the need to build a broad political and public consensus. In this sense, UAS provide increased political control that extends to three levels (Dawkins, 2005:21-24). First, they improve the 
control of the timing and pace of operations inasmuch as they minimize external interference. Second, they enhance the control over the political debate regarding the use of force. Finally, they increase the perception of precise control from the strategic level to the tactical employment of forces, encouraging greater interference in every detail of the conduct of war.

Thus, war becomes a political solution, even more prominent because less demanding, easily justifiable and acceptable. This is even truer for the option of single-handedly use of Remote Air Warfare. By limiting casualties and eliminating the possibility of prisoners of war, UAS allow for a more discreet planning and execution of missions in remote areas, without the burden of previous media exploitation, maximizing also the operational surprise of the attacks.

In addition, the withdrawal of forces from current theaters and the increasing production of UAS create a surplus of systems which may be allocated to other contingencies, reflecting a concern associated with the proliferation of weapons systems: the more UAS available, the greater the tendency for their use.

\section{Physical detachment and emotional disconnection of the virtual warriors}

We face a new era of telewarfare. The physical and emotional disconnect associated with this type of remote operation, similar to a video game, threatens to change the decision-making dynamics, raising concerns about the basic principles of morality and humanity that precede the decision to kill an opponent.

One of the implications resulting from the increase of distance between combatants is that it may cause desensitization to death similar to the one experienced in video games. This "Playstation combat mentality", by individuals who have never been exposed to the risks and rigors of war, can lead to excesses and disrespect of international conventions (Alston, 2010:25). The fear that war can be transformed into a video game is overly simplistic. However, this argument relies on the assumption that when we don't have to physically face the opponent, it becomes easier to kill.

Actually, there is a historical trend for decreasing the resistance to killing in combat as distance increases between combatants (Grossman, 1996). That is, the farther the opponent is, the easier it is to kill him. For example, the resistance to impose death by air bombing from $20,000 \mathrm{ft}$ or through the use of artillery located at $2 \mathrm{~km}$ from 
the target, is minimal (Grossman; Christensen, 2008:203). At these distances, the depersonalization of the target facilitates the use of weapons, rending war as highly impersonal. However, when distance increases, the psychological effect on the enemy is reduced, if compared with fighting at close range, in particular by the fear of being killed in close combat, which modifies the behavior of the opponent (Ibidem:204). In this sense, the personal view of death and destruction becomes extremely effective in modifying human behavior. Moreover, weapons which constitute a direct threat are psychologically more effective than weapons of area. That is, the sniper is psychologically more effective than a volley of machine gun, just like a precision bomb has a more profound psychological impact than a barrage of artillery fire (Ibidem:204). Similarly, the constant anticipation of being killed can have a detrimental effect, particularly when this uncertainty is prolonged in time (Ibidem:273).

We can thus conclude that, despite the increased distance, the more accurate the weapon is, the greatest fear it inspires in the opponent. By adding stealth ability to this, thus surprise and uncertainty about the arrival of death, it is possible to extreme the psychological effect on the enemy. It is in this perspective that the almost ubiquity of precision bombing reveals the devastating psychological effects of Remote Air Warfare.

Although an increase in distance between combatants can induce a depersonalization of combat, Gregory (2011) advocates a contrasting phenomenon of personalization of combat resulting from an emotional closeness with friendly forces on the ground. Despite this paradox, both phenomena contribute to increase the predisposition to use lethal force and likewise the risk for non-combatants.

Firstly, despite being thousands of miles away from the physical target, the high definition view of the battle space gives operators a sense of proximity to the action. As a result, this proximity effect acquired from multisensory stimuli (image and audio) increases, on the one hand, the situational awareness of operators, but on the other hand, personalizes the fight making it more intimate, especially when friendly forces are under attack. The nearly microscopic vision of targets and destruction in high resolution appears to contribute to aggravate this symptom, since the video console displays not only the destruction imposed, but also the complete sequence of events, unlike the ephemeral presence of the pilot in the target area. Thus, the conceptual dichotomy of distance, which simultaneously separates operators physically, but psychologically immerses them in combat, may contribute to precipitate the use of deadly force against elements in the vicinity of 
friendly forces, increasing the risk of imposing additional suffering to the population.

Another factor worth highlighting is the enemy dehumanization process, which as one of the constants of war, lowers the barriers of combat, either from the society or from its own military that imposes the opponent's death. By removing the human nature from the adversary, such as the demonization of the opponent, one can disinhibit the actions of the offender, favoring the execution of violent acts that otherwise would not be considered nor acceptable (Bandura, 2004:135-137). Following this reasoning, authors like Wilson (2011) argue that the psychological alienation resulting from the conduct of Remote Air Warfare requires a new form of dehumanization of the adversary. To him, keeping the distance from human agony transforms real war into a brutal simulation. For example, the reference to the insurgents killed in Pakistan as "bugsplat", emphasizes the psychological technique of dehumanization of targets, reducing the inhibition to kill and making death more acceptable.

This synthetic combat environment facilitates the dehumanization of the enemy and as such, the moral disconnection of operators, which in turn is reflected in the desensitization to death and increased likelihood of unethical behavior. In a technological perspective, the immersion in this virtual reality environment blurs the differences between reality and video games, confusing real targets with virtual ones, while at the ethical level it causes a physical and emotional distancing from the actions produced. In this extreme scenario, the operator will also be dehumanized, deprived of the moral sense of responsibility or guilt for his actions (Royakkers; Est, 2010:293). With the increasing autonomy of UAS and the perspective of gradual human transition from the role of executant to that of supervisor, it is possible to anticipate the worsening of this condition (Ibidem:292).

Nonetheless, there are several mechanisms which can serve to humanize the conduct of Remote Air Warfare. The rules of operation of UAS try to emulate the routines characteristic of a manned mission. USAF does everything it cans to ensure that UAS operators behave in the same way as pilots of manned aircraft. From the uniforms to the mission briefing, attempts to replicate the combatant "ethos" (Bushey, 2011). Conducting a virtually risk-free task requires additional discipline by operators, including adherence to rules of engagement, as well as adds supervisory challenges. To minimize the strategic effects of possible collateral damage, the political and military leadership continues to impose constraints and restrictions on the use of weapons, tactics and target selection protocols. 
This change in the demographics of war, with the inclusion of a new generation with distinct military attributes, forces us to rethink the military ethos so as not to dilute the moral and ethical standards of the armed forces and the relationship of society with war. In that regard, the Western dependence on the use of UAS can influence the perception and connection of societies with war. In a society where the draft was eliminated, where declarations of war have ceased to exist, and where defense budgets are no longer a priority, the withdrawal of human combatants from the battle space hastes the elimination of the ultimate political and social costs for waging war.

\section{Conclusion}

Remote Air Warfare challenges the dominant paradigm of manned aircraft, changing the form and lethality of combat, the identity of the fighter and the experience of war itself. The introduction of a capability in war which allows a future where fight is dehumanized and conducted remotely and autonomously has profound impacts on the phenomenon of hostile conflict. This operational template translates the double moral implications of the increasing distance and removal of human risk of the duel. Even though it confirms the historical trend of increasing physical distance between combatants, accompanies it with a psychological disconnection. On the other hand, there is a political maneuver's expansion of freedom, increasing the propensity to wage war.

When accomplishing an analysis about the political calculus, we are inclined to confirm that Remote Air Warfare increases the political desire to use force, not as a last resort but as the first choice. In this sense, the preeminence of Remote Air Warfare helps changing the strategic culture of states to resort to coercive force in order to achieve political goals, increasing the desire to employ airpower as a preferential and almost exclusive instrument for future wars.

In democratic states, public opinion is a conditioning factor and regulatory force of the political ambitions of the regime. Furthermore, the tolerance for casualties in combat becomes an indicator of the risk that society is willing to take. This risk aversion is exacerbated by the emergence of Remote Air Warfare, since it further contributes to reduce the tolerance for casualties, perhaps to a point where direct combat between men is banned. However, a more realistic view foresees a greater political propensity to resort to the military instrument, as the first solution to a crisis, thereby contributing to the proliferation of conflicts, increasing the hostility 
and danger in an already complex and adverse future environment for international relations.

The proliferation of armed drones entails the concerns that, by distancing ourselves from the horrors of war, we may relax some of the crucial barriers that prevent the spread of armed conflict. In other words, from a political perspective, it renders the use of the military instrument even more attractive, and increases the chances of further damage and suffering to civilians. In this case, the adverse effects of persistent surveillance and precision create a presumption of infallibility that motivates riskier political decisions, such as the attacks in urban areas. The alternation between proximity (intimacy with the events) and distancing (physical distance from battle space), together with an expanded temporal permanence, add more complexity to the analysis of the effects of Remote Air Warfare on the individual decision making process. That is, the improvements in the ability to transmit real-time video distort the distance effects between the operator and the target, qualitatively risking the innocent. In addition, these factors (proximity, remoteness, permanence), never present simultaneously in the history of warfare, paradoxically affect the paradigm of Remote Air Warfare. Despite their ambivalence, these factors contribute to reduce the barriers for the use of lethal force, simplifying the decision to kill.

Throughout this study we have unveiled that the inevitable spread of Remote Air Warfare may induce a fundamental transformation of war. In addition to changing the way of fighting, in terms of capability, operational efficiency and lethality, it also changes the prototype of the fighter, qualitatively transforming human interference in war and the experience itself, both individually and as a political tool and ultimate expression of the interaction between societies.

\section{Bibliography}

Alston, Philip, 2010. Study on targeted killings. United Nations: New York.

Bandura, A, 2004. The role of selective moral disengagement in terrorism and counterterrorism. In Mogahaddam, F et al., eds. Understanding terrorism: Psychosocial roots, consequences and interventions. American Psychological Association: Washington DC.

Biddle, S, 2004. Military Power. Princeton University Press: Princeton.

Biddle, T, 2002. Rhetoric and Reality in Air Warfare. Princeton University Press: Princeton. 
Brennan, John, 2012. Brennan's Speech on Counterterrorism. Council on Foreign Relations. [Accessed 18 FEB. 2013]. Available at http://www.cfr.org/counterterrorism/brennans-speech-counterterrorism-april2012/p28100.

CBO Study, 2011. Policy Options for Unmanned Aircraft Systems. Congressional Budget Office: Washington DC.

Clark, Richard, 2000. Uninhabited Combat Aerial Vehicles. Air University Press: Montgomery.

Clausewitz, Carl von, 1989. On War. Edited and translated by Michael Howard and Peter Paret. Princeton University Press: Princeton.

Cohen, E, 2007. Technology and Warfare. In Baylis, J et al., ed. Strategy in contemporary world: An Introduction to Strategic Studies. Oxford University Press: Oxford.

Dawkins, James, 2005. Unmanned Combat Aerial Vehicles: Examining the Political, Moral, and Social Implications. School for Advanced Air and Space Studies: Montgomery.

Dunlap, Charles, 1999. Technology and the 21st Century Battlefield. Strategic Studies Institute: Carlisle.

Ehrhard, Thomas, 2010. Air Force UAVs: The Secret History. Mitchell Institute: Arlington.

Gear, J, 2011. USAF RPA Update: Looking to the Future. Headquarters, United States Air Force: Washington DC.

Geete, Stephanie, 2009. Full-spectrum of Aviation Brigade assets combine for UAV recovery mission. US Army online. [Accessed 18 FEB. 2013]. Available at http://www.army.mil/article/15979/full-spectrum-of-aviationbrigade-assets-combine-for-uav-recovery-mission/.

Gertler, Jeremiah, 2012. U.S. Unmanned Aerial Systems. Report for Congress. Congressional Research Service: Washington DC.

Gregory, Derek, 2011. Lines of Descent. Open Democracy. [Accessed 18 FEB. 2013]. Available at http://www.opendemocracy.net/derek-gregory/lines-ofdescent.

Grossman, Dave, 1996. On Killing: The Psychological Cost of Learning to Kill in War and Society. Little Brown: New York.

Grossman, Dave; Christensen, Loren, 2008. On Combat: The Psychology and Physiology of Deadly Conflict in War and in Peace. Warrior Science Publications: Milstadt.

Hurley, A, 1975. Billy Mitchell: Crusader for Air Power. Indiana University Press: Bloomington.

Keegan, John, 1994. A History of Warfare. Alfred A. Knopf: New York.

New American Foundation, 2012. The Year of the Drone. [Accessed 18 FEB.

2013]. Available at WWW: <URL:

http://counterterrorism.newamerica.net/drones $>$.

Nolin, Pierre, 2012. Unmanned Aerial Vehicles: opportunities and challenges for the alliance. NATO: Brussels. 
Olsthoorn, Peter; Royakkers, Lambèr, 2011. Risks and Robots - some ethical issues. Seminar "The Ethics of Emerging Military Technologies". International Society for Military Ethics: University of San Diego.

Royakkers, Lambèr; Est, Rinie van, 2010. The cubicle warrior: the marionette of digitalized warfare. Ethics and Information Technology. Vol. 12, no. 3, 289296.

Schanz, Marc, 2011. The Reaper Harvest. Air Force Magazine. Vol. 94, no. 4, 3639.

Singer, Peter, 2009. Wired for War. Penguin Press: New York.

The Bureau of Investigative Journalism, 2012. Covert War on Terror: the data. [Accessed 18 FEB. 2013]. Available at WWW: <URL: http://www.thebureauinvestigates.com/category/projects/drone-data/.

US DoD, 2010. 2010 Quadrennial Defense Review Report. Department of Defense: Washington DC.

US DoD, 2012a. Sustaining US Global Leadership: Priorities for $21^{\text {st }}$ Century Defense. Department of Defense: Washington DC.

US DoD, 2012b. Report to Congress on future Unmanned Aircraft Systems training, operations, and sustainability. Department of Defense: Washington DC.

US GAO, 2012. Nonproliferation: Agencies Could Improve Information Sharing and End-Use Monitoring on Unmanned Aerial Vehicle Exports. US Government Accountability Office: Washington DC.

USAF, 2009. Unmanned Aircraft Systems Flight Plan 2009-2047. Headquarters, United States Air Force: Washington DC.

Vasquez, J, 1993. The War Puzzle. Cambridge University Press: Cambridge.

Wilson, G., 2011. The Psychology of Killer Drones - action against our foes; reaction affecting us. [Accessed 18 FEB. 2013]. Available at http://fabiusmaximus.wordpress.com/2011/09/28/29263/.

Zenko, Micah, 2010. Addicted to Drones. Foreign Policy. [Accessed 18 FEB. 2013]. Available at http://www.foreignpolicy.com/articles/2010/10/01/addicted_to_drones. 